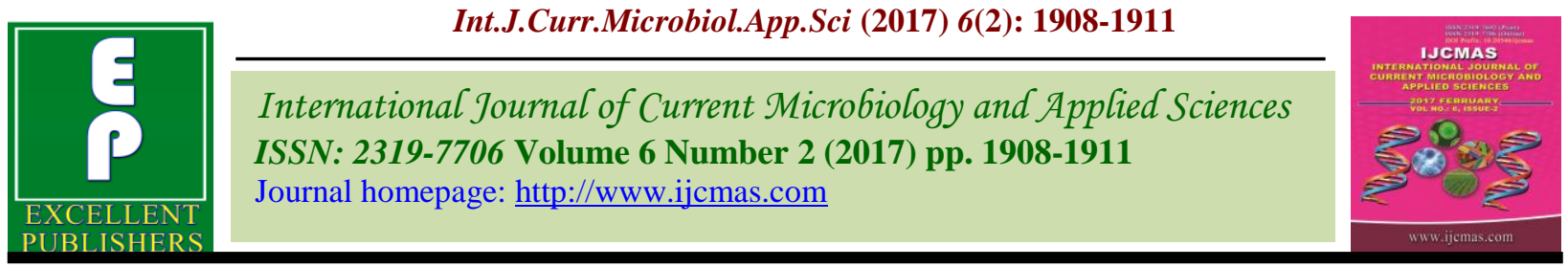

Original Research Article

http://dx.doi.org/10.20546/ijcmas.2017.602.216

\title{
Comparative Study on Biochemical Markers: Patients Infected By Dengue Virus
}

\author{
R. Aruna ${ }^{1}$ and M. Prakash ${ }^{2 *}$ \\ ${ }^{1}$ Research and Development Centre, Bharathiar University, Coimbatore-641 046, \\ Tamil Nadu, India \\ ${ }^{2}$ Department of Microbiology, Kanchi Shri Krishna College of Arts and Science, \\ Kilambi, Kancheepuram-631 551, Tamil Nadu, India \\ *Corresponding author:
}

\section{Introduction}

Dengue is a vector borne viral infection that belongs to family Flaviviridae. It is a single stranded RNA virus and endagers 2.5 billion people worldwide. WHO has estimated about 50 million cases of dengue infection every year worldwide. After the incubation period of 4 - 7 days (range 3- 14 days) symptoms appear with sudden onset of fever that lasts for 3- 5 days with headache, myalgia, anorexia, Gastrointestinal tract infection and rash (Anderson, et al., 2008). The viruses are transmitted to man by the bite of infected mosquito, mainly Aedis aegypti. Liver dysfunction in Dengue is due to direct effects of the virus on liver cells and an adverse effect of host immune reaction against the virus (Burke, et al., 1998). Virus has been identified in liver tissue and dengue antigen identified within liver cells of affected individuals leading to kupffer cell hyperplasia. Dengue viral antigens are mostly found in the liver cells surrounding necrotic areas of the liver. Apoptotic hepatocytes are found to be colocalised with dengue virus infected hepatocytes, suggesting that hepatocytes are the major site of dengue virus replication in the liver (Claro, et al., 2004; Coller, et al., 2010). Therefore, the aim of the present study is to analyse the role of liver enzymes in Dengue viral infection. 


\section{Materials and Methods}

The present study was carried out in Indira Gandhi Government General Hospital and Post Graduate Institute, Puducherry. 486 dengue positive patients were chosen from the hospital from the period of September 2014 to January 2015. $2 \mathrm{ml}$ of venous blood was collected from these patients. The collected samples were centrifuged at $2000 \mathrm{rpm}$ for 2 $\min$.

The patients with febrile illness were screened for dengue by ELISA technique using standard kits, for NS1Ag and NIV Pune kit for IGM screening as per the manufactures instructions. The serum samples of positive patients were stored at $-40^{\circ} \mathrm{C}$ for further study.

The samples were processed for SGOT (serum glutamic oxaloacetic transaminase) and SGPT (serum glutamic pyruvic transaminase) by UV enzymatic kinetic method as per standard procedures (Graham, et al., 1999). The values were recorded by spectro photometry. Water sample was treated as control and the positive and negative controls were calibrated. The absorbance was recorded for the samples and the values were noted.

\section{Results and Discussion}

The normal value for SGOT and SGPT is 0 $60 \mathrm{IU} / \mathrm{L}, 0-50 \mathrm{U} / \mathrm{L}$ respectively. The value of the children affected with dengue was found to be raised than the normal level. On the other hand the normal patients do not have the elevated levels of neither SGOT nor SGPT values. The results of biochemical studies shows that mean value of SGOT in healthy control is 22.75 and S.D value is \pm 6.00 while SGPT is between $12-30 \mathrm{IU} / \mathrm{L}$, mean value is 19.4 and its S.D value is \pm 5.59 . In dengue infected subjects mean value of SGOT is 180.15 and S.D value is \pm 94.90 and SGPT is 53-390 IU/L, mean value is 153.7 and S.D value is \pm 86.67 , of 486 dengue infected patients, suffered from NS1Ag parameter was affected more than the other parameters such as $\operatorname{IgM}$ and $\operatorname{IgG}$, the results were illustrated in Figure.1 The age wise distribution of raised SGOT and SGPT values were presented in the Figure. 2.

Very little raises in SGOT values as it is the marker of severe liver damage it may not influence the dengue virus infection. Only 24 cases were found little raise in the SGOT values. That too no $\mathrm{IgG}$ reactive patient was found to have increased SGOT value.

Fig.1 Comparison of SGOT and SGPT values in serological parameters of dengue

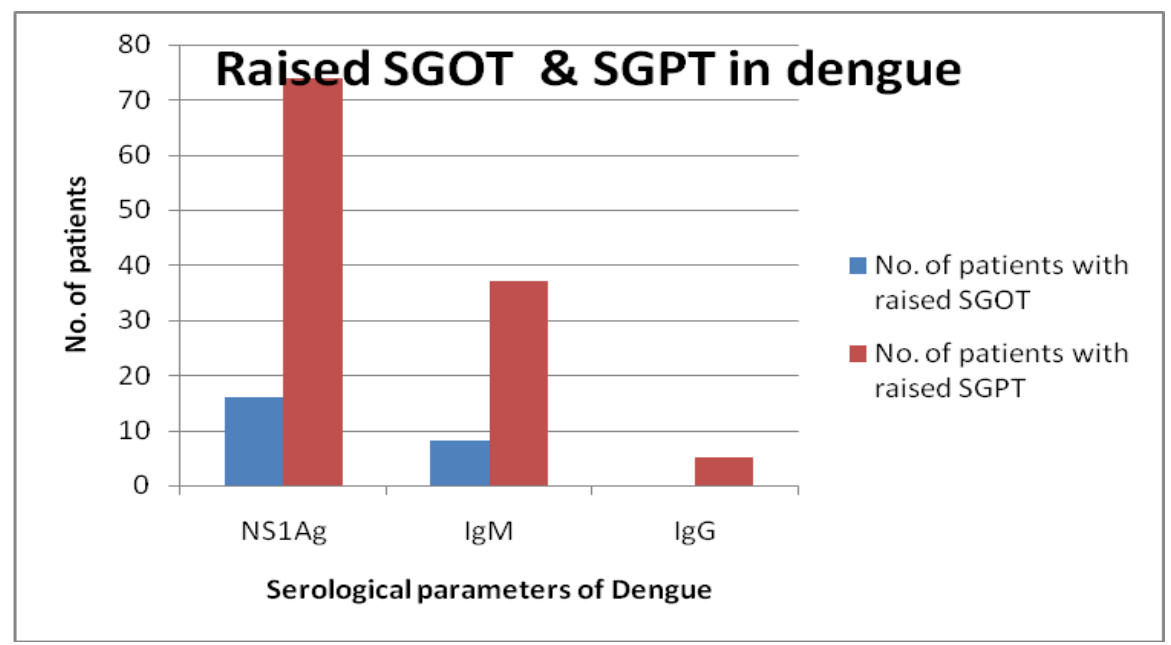


Fig.2 Age wise distribution of Raised SGOT and SGPT levels in dengue patients

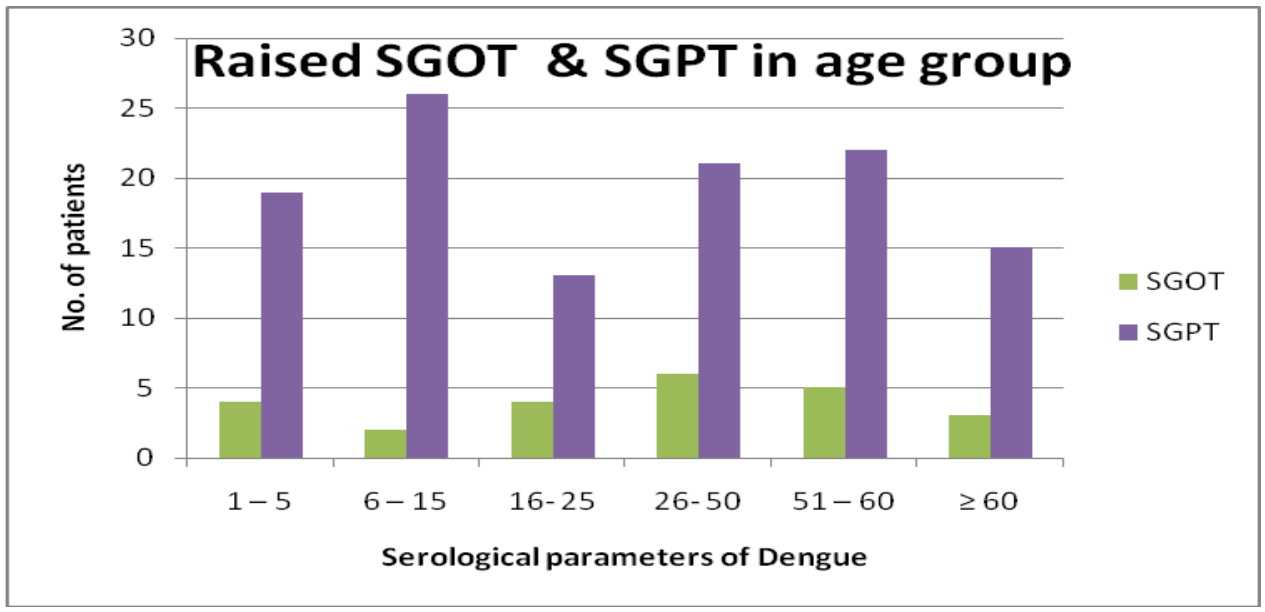

Fig.3 Comparison of SGOT values among dengue patients with respect to serological parameters

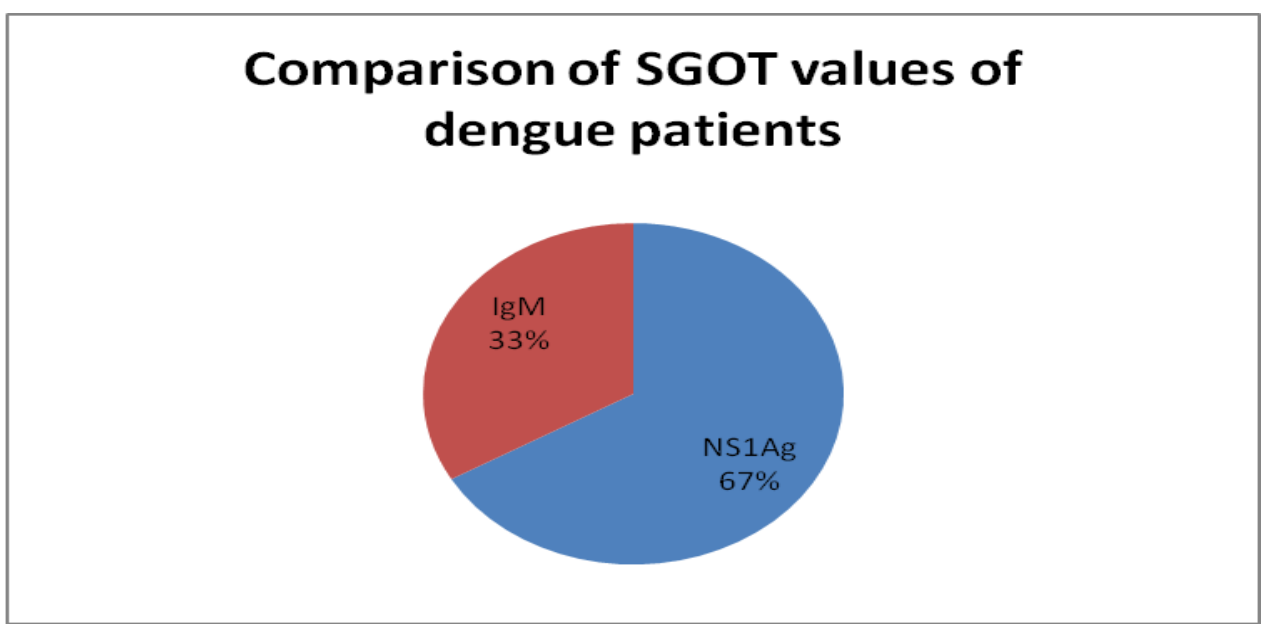

Fig.4 Comparison of SGPT values among dengue patients with respect to serological parameters

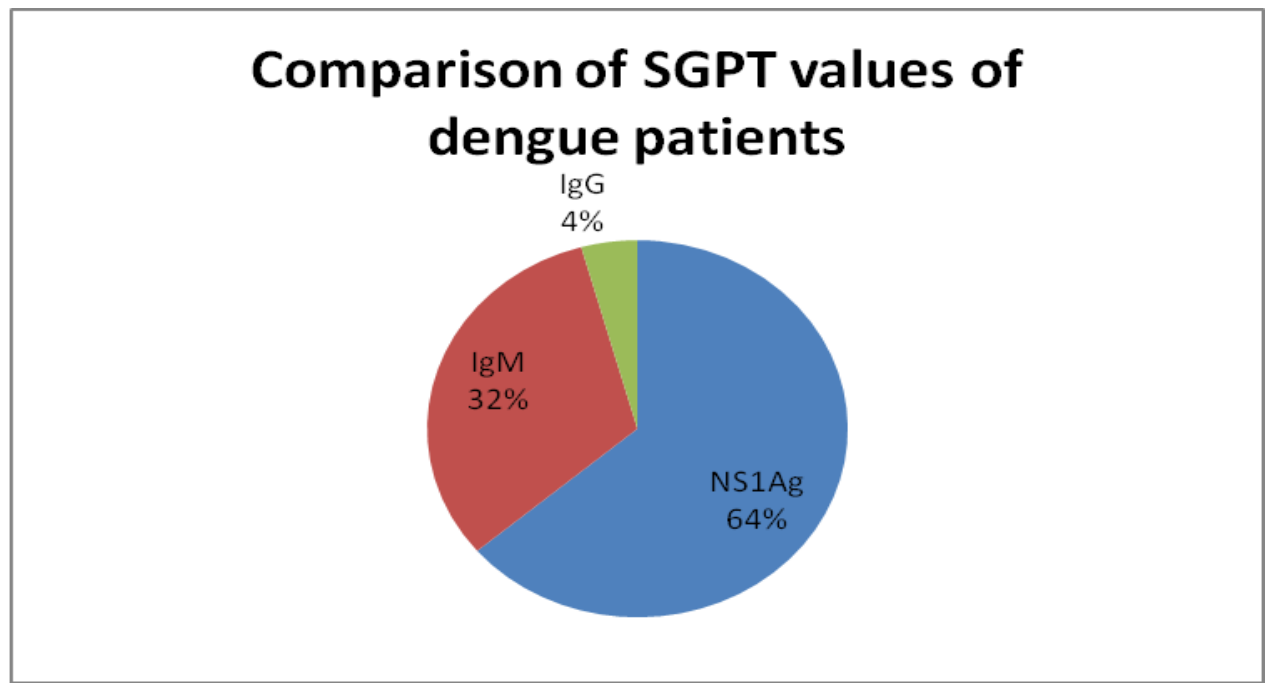


As in the case of SGPT, 24\% of dengue patients were found to have increased SGPT values as it the marker for liver tissue damage due to fever. The results of age wise distribution were found to be high in the age group of 6- 15 and low in the group of $16-$ 25. The age group such as 26 -50 and 51-60 has shown the similar results. Patient with all the three parameters were found to be a little raise in the SGPT values. The distribution of Raised SGOT \& SGPT levels with respect to serological parameters of Dengue were depicted the Figures $3 \& 4$.

SGOT is usually a marker for chronic liver disease. SGOT is an enzyme that located in heart muscle, smooth muscle, liver cells, etc. SGPT is usually as a marker for acute liver disease. SGPT only located in liver cells. The biochemical markers i.e SGOT and SGPT were higher with dengue patients than those with non dengue febrile conditions. The degree of liver dysfunction in dengue infection varies from mild injury with elevation of aminotransferases alone to severe injury with jaundice and even fulminate hepatic failure. The study results show that the SGPT value may be a test which is indicative of dengue hemarogic fever. Since SGOT value was associated severe liver dysfunction, raise in SGOT value was not seen in this present study. The age wise distribution results showed that the SGPT level was found to be high in the age group of 16- 15 this may be because of the poor development of the organs as they are child group. And the less number of raised SGPT values were shown in the group of $16-25$ this was may be because of matured development of liver and other organs etc., The similar result was also indicated by Cook, 1997; Dowd and Pierson, 2011. Of dengue cases the NS1Ag patients have more SGPT value than IgM and IgG. This may be due to the development of antibodies by our immune system.

\section{References}

Anderson, R., King, A.D. nad Innis, B.L; Correlation of $\mathrm{E}$ protein binding with cell susceptibility to dengue for virus infection. Journal of General Virology; 73(1): 21552159.

Burke, D.S., Nisalak, A. and Johnson, D.E;1998.A propective study of Dengue infections in Bangkok. American Journal of Tropical Medicine and Hygiene;38(1):172180.

Claro, L.B, Tomassini, H.C. and Rosa, M.L. 2004. Dengue prevention and control:a review of studies on knowledge, beliefs and practices. Cadernas de saude publica. 20(6):1447-145.

Coller, B.A., Clements. D. E., Martyak, T., Yelmene, Thorne, M. and Parks, D.E. 2010. Advances in falvi virus vaccine development. Drugs;13(12):880-4.

Cook, G. C. 1997.Liver involvement in systemic infections. European Journal of Gastroenterology and Hepatology. 9(12):1239-47.

Dowd, K.A. and Pierson, T.C. 2011. Antobody mediated neutralization of falvi viruses: a reductionist view.Virology;411(2):30615.

Graham, R.R., Juffrie, M. and Tan,R;1999.A prospective seroepidemiologic study on dengue in children four to nine years of age in Yogyakarta, Indonesia I. American Journal of Tropical Medicine and Hygiene;61(3):412-419.

\section{How to cite this article:}

Aruna, R., and Prakash, M. 2017. Comparative Study on Biochemical Markers: Patients Infected By Dengue Virus. Int.J.Curr.Microbiol.App.Sci. 6(2): 1908-1911. doi: http://dx.doi.org/10.20546/ijcmas.2017.605.216 